\title{
Cell wall remodeling under abiotic stress
}

\section{Raimund Tenhaken *}

Department of Cell Biology, Plant Physiology, University of Salzburg, Salzburg, Austria

\section{Edited by:}

Thorsten Hamann, Norwegian

University of Science and

Technology, Norway

Reviewed by:

Ian S. Wallace, University of Nevada,

Reno, USA

Peter Ulvskov, Copenhagen

University, Denmark

Jose Manuel Estevez, University of

Buenos Aires and CONICET,

Argentina

*Correspondence:

Raimund Tenhaken, Department of Cell Biology, Plant Physiology,

University of Salzburg,

Hellbrunnerstr. 34, 5020 Salzburg,

Austria

e-mail: raimund.tenhaken@sbg.ac.at
Plants exposed to abiotic stress respond to unfavorable conditions on multiple levels. One challenge under drought stress is to reduce shoot growth while maintaining root growth, a process requiring differential cell wall synthesis and remodeling. Key players in this process are the formation of reactive oxygen species (ROS) and peroxidases, which initially cross-link phenolic compounds and glycoproteins of the cell walls causing stiffening. The function of ROS shifts after having converted all the peroxidase substrates in the cell wall. If ROS-levels remain high during prolonged stress, $\mathrm{OH}^{\circ}$-radicals are formed which lead to polymer cleavage. In concert with xyloglucan modifying enzymes and expansins, the resulting cell wall loosening allows further growth of stressed organs.

Keywords: abiotic stress, peroxidase, xyloglucan endotransglucosylases/hydrolases, reactive oxygen species, boron

\section{INTRODUCTION}

Abiotic stress in plants refers to growth conditions which are unfavorable for growth. Traditionally, these conditions include temperature stress (either cold or heat) as well as drought, osmotic stress and salinity. The latter stress factors are tightly associated with scarce water resources, a major challenge for future farming given the predicted increase of human population in the next decades (Rosegrant and Cline, 2003). Furthermore, an imbalance in nutrients (e.g., boron) in the soil can be an important abiotic stress factor affecting plant cell walls (Wimmer and Eichert, 2013). In nature, plants may be exposed to several stress conditions at the same time (Mittler and Blumwald, 2010). Atkinson and Urwin (2012) found evidence that the plant response to multiple environmental stresses is distinct from that of individual stress factors and not just additive.

Cell wall dynamics is not easy to analyze and as a consequence the majority of studies about cell wall modifications under abiotic stress focus primarily on genes putatively involved in cell wall metabolism. The improvement of proteomics technologies has further led to studies in which the plant proteome is compared between stressed and control plants including a few studies focusing on the cell wall proteome (Dani et al., 2005; Zhu et al., 2007; Kong et al., 2010; Shinano et al., 2011; Komatsu and Yanagawa, 2013). The changes in the cell wall itself are only barely studied.

Most plants stop growing upon exposure to severe drought, osmotic stress or salt stress (Skirycz and Inze, 2010). In aerial parts of plants the cessation of growth usually occurs earlier than in the root system (Wu and Cosgrove, 2000) allowing the stressed plants to invest available resources into root growth to explore residual water in the soil. Growth of plant organs is based on cell division in the meristematic zones followed by a tremendous expansion of new cells in a complex turgor driven process
(Schopfer, 2006). Therefore, it is obvious that any reduction in cell turgor, caused by osmotic stress, also reduces the mechanical power of the cell to expand the polysaccharide network.

\section{THE PLANT CELL WALL}

Plant cell walls are composed of carbohydrate polymers, lignin and structural proteins in variable amounts. The cell wall is of critical importance for the cell shape and provides mechanical strength to withstand the turgor pressure. Furthermore, the cell wall is the front line for attacking pathogens. In primary cell walls all these functions need to be compatible with the expansion of cells during plant growth. Numerous excellent reviews about cell wall biology have been published over the years (Carpita and Gibeaut, 1993; Cosgrove, 1997; Reiter, 2002; Wolf et al., 2012; Braidwood et al., 2014). Many models of plant cell walls have been described which try to integrate all compositional and structural details which have emerged from the many studies on plant cell walls. Certainly there is no universal model which applies for all cell walls but a number of common principles have been discovered which are present and important in larger groups of plants. Primary cell walls consist of cellulose, a diverse group of different hemicelluloses binding to cellulose and pectins. The cellulose content in primary cell walls is rather low (often below 20\%) but it provides mechanical strength for load bearing. In order to fulfill this function, the cellulose fibrils need to be cross-linked by hemicelluloses (Cosgrove, 1997; Wolf et al., 2012) and possibly also by pectins (Mohnen, 2008; Peaucelle et al., 2012). Xyloglucans are the major hemicellulosic polymers of dicot plants that bind to cellulose fibrils. Existing models suggest the binding of each xyloglucan polymers to at least two cellulose fibers (Cosgrove and Jarvis, 2012). This interaction can be modulated by two groups of enzymes, expansins and 
xyloglucan endotransglucosylases/hydrolases (XTH). The major group of polymers in primary dicot cell walls are pectins, a heterogeneous group of homogalacturonic acid, rhamnogalacturonan I (RG-I) and rhamnogalacturonan II (RG-II) (Mohnen, 2008). Homogalacturonic acid is a polymer of galacturonic acid, ionically cross-linked by $\mathrm{Ca}^{++}$, when the carboxygroup is not methylated. RG-I has a heteropolymeric backbone with alternating rhamnose and galacturonic acid molecules. An important feature of RG-I are the decorating side chains of arabinan or galactan (Mohnen, 2008). RG-II is a highly complicated polymer with a polygalacturonic backbone and four distinct side chains. Initially, pectins were mostly regarded as filling material for the open space in the cellulose /hemicellose network but newer studies point to important structural roles (Peaucelle et al., 2012). One of the oldest observations for this is the role of boron for cell walls (Lee and Aronoff, 1966) (see below), which is crosslinking pectic RG-II-molecules (Ishii et al., 1999). Without proper RG-II-interaction, the cell walls swell and increase in thickness concomitant with an increase in pore size (Fleischer et al., 1999).

\section{PEROXIDASES}

Cell walls contain a number of structural proteins, as well as hemicellulosic polymers with attached phenolic residues like ferulated arabinoxylans, which can be cross-linked by the action of cell wall peroxidases (Lindsay and Fry, 2008; Burr and Fry, 2009). A number of studies have found peroxidases to be induced by osmotic stress (Simonovicova et al., 2004; Csiszar et al., 2008, 2012; Pechanova et al., 2010; Ranjan et al., 2012; Maia et al., 2013). By comparing wheat cultivars with different drought tolerance Csiszar et al. (2012) found higher transcripts levels for TaPrx01, TaPrx03, TaPrx04 cell wall bound peroxidases in the drought tolerant variety when exposed to osmotic stress. The total peroxidase enzyme activity for covalently bound peroxidases under osmotic stress, using guaiacol as a substrate, was however higher in drought sensitive cultivar. A similar increase in peroxidase in cowpea was attributed to the inhibition of root growth under salinity (Maia et al., 2013), whereas a moderate dehydration did neither increase the cell wall bound peroxidase activity nor the root growth. A study performed with cotton roots found high peroxidase transcript levels mainly in two drought tolerant cultivars (Ranjan et al., 2012) whereas these genes are much lower expressed in two drought sensitive lines. A comparison of two wheat cultivars differing in their drought stress resistance also showed an increase in transcript levels of several peroxidases in the more resistant cultivar (Secenji et al., 2010). It was assumed that peroxidase in this system is more involved in scavenging hydrogen peroxide rather than in modifying the cell wall. The sensitive cultivar shows higher transcript levels for glutathioneS-transferases, which might be less efficient in removing reactive oxygen species. In a search for peroxidase genes from sweet potato Kim et al. (2008) identified one isoform (SWPA4) that is strongly induced by several abiotic stresses. They overexpressed the gene in tobacco plants and found a highly elevated peroxidase enzyme activity in the cell wall leading to transgenic plants which are more tolerant against salt and drought stress.

Peroxidases need $\mathrm{H}_{2} \mathrm{O}_{2}$, a common reactive oxygen species (ROS) in plants, as a co-substrate. ROS have been observed to be a typical plant response to osmotic stress (Miller et al., 2010) thereby matching the demand for the co-substrate of peroxidases. If both, the increase in peroxidase activity and the formation of ROS, occurs in the same tissue, cross-linking of cell wall components might strengthen the mechanical properties of the wall (Kieffer et al., 2000; Passardi et al., 2005; Wakabayashi et al., 2012). Cross-linking likely occurs between cell wall glycoproteins but also between phenolic compounds present in the wall in particular ferulic acid esterified to arabinoxylans in grasses (Lindsay and Fry, 2008; Burr and Fry, 2009). As this type of cross-linking is based on covalent linkages it can usually not been reversed. A more or less local stiffening of the cellular structure has occurred which is accompanied with a cessation of growth (MacAdam and Grabber, 2002; Wakabayashi et al., 2012; Uddin et al., 2014). This might be beneficial for plant cells to better withstand the changes in turgor pressure of osmotic stress. As discussed below the loosening of cell wall polysaccharides seems to be very important under osmotic, drought or salt stress to maintain the possibility for cells and organs to expand. The other face of ROS is the formation of $\mathrm{OH}^{\circ}$ radicals, which are capable of cleaving sugar bonds in plant polysaccharides (Fry, 1998; Schopfer, 2001; Renew et al., 2005). This causes a cell wall loosening similar to the action of classical loosening enzymes like expansins or xyloglucan modifying enzymes (Renew et al., 2005).

The apparently contradicting observations about peroxidase activity under drought stress should be examined in broader sense, which considers all, peroxidase activity, substrates and ROS as a unit. The balance between these factors may well explain the different results observed in plant studies with abiotic stress. An excess of peroxidase activity, cross-linkable substrates and sufficient amounts of $\mathrm{H}_{2} \mathrm{O}_{2}$ will favor the local stiffening of the wall, reduce cell wall expansion and thus strengthen the mechanical stability of the cells and organs. If however $\mathrm{H}_{2} \mathrm{O}_{2}$ transiently accumulates in the presence of copper or iron in the cell wall, which are typically present in cell walls in sufficient amounts, and the peroxidase activity or the substrate availability is limited, the formation of $\mathrm{OH}^{\circ}$-radicals will be favored. This will cause disruption of sugar polymers of the cell wall with a concomitant weakening in the mechanical properties of the wall (Fry, 1998).

\section{XYLOGLUCAN MODIFICATION}

The xyloglucan endotransglucosylases/hydrolases (XTH) mediated cell wall remodeling is based on a widely proposed cell wall model, in which xyloglucans act as tethering polymers between load bearing cellulose fibrils (Hayashi, 1989). The most striking cell wall related phenotype observed in osmotically stressed plant cells is the increased expression of expansins and/or xyloglucan modifying enzymes (XTH) (Rose et al., 2002). Cho et al. (2006) have expressed a XTH gene from Capsicum annuum (CaXTH) constitutively in Arabidopsis, which was previously identified as an abiotic stress (cold, drought, salt) induced gene in hot pepper. The strong reduction in root length observed in control seedlings of Arabidopsis on salt-containing media is less pronounced if the CaXTH gene is expressed. However, aberrant leaf morphology (curled leaves) was found in several independent lines and transverse sections of leaves showed an irregular cell pattern compared to wild type plants. The same CaXTH gene 
was later expressed in tomato plants without phenotypical side effects (Choi et al., 2011). Again the transgenic tomato seedlings showed a strongly increased salt tolerance with longer roots. The exact mode of action was not determined but the authors speculate about a beneficial cell wall strengthening of mesophyll cells, protecting them from excessive water loss. In addition, they suggest an important role of the XTH activity in remodeling the cell wall of stomata possibly preventing excess water loss. Arabidopsis plants with a reduced level of cytokinin are more salt tolerant than the wild type. A transcriptome profiling identified numerous genes upregulated in the tolerant mutant, among them XTH genes and glycoside hydrolases (Nishiyama et al., 2012). Rice plants exposed to abiotic stress (cold, heat, drought) showed a strong increase in transcripts for OsXET9, a xyloglucan modifying enzyme that might serve as a general stress marker gene (Dong et al., 2011). Arabidopsis plants overexpressing a mannose-6phosphate reductase have increased levels of mannitol and are more tolerant to abiotic stress. Transcriptome analysis identified numerous cell wall modifying genes, which are upregulated in these plants among them xylosyltransferases involved in xyloglucan biosynthesis as well as XTH members. The authors concluded that these genes are ineeded for cell growth and cell wall strengthening as a response to the accumulating mannitol (Chan et al., 2011). Thus, many abiotic stress conditions lead to an increase in one or a few XTH genes. Expression pattern for XTH genes in Arabidopsis under such stress conditions are shown in Figure 1.

The xyloglucan-cellulose interaction cell wall model was recently challenged by the generation of a novel double-mutant $x x t 1 / x x t 2$ in Arabidopsis, which lacks classical xyloglucan due to a disruption of both xyloglucan xylosetransferases $(X X T)$ genes (Cavalier et al., 2008). The mutant has a surprisingly normal phenotype considering the attributed major role of xyloglucan for the stability of the primary cell wall. Biomechanical measurements however showed a reduced stiffness. The $x x t 1 / x x+2$ mutant has led to a rethinking of the role of xyloglucan polymers in primary

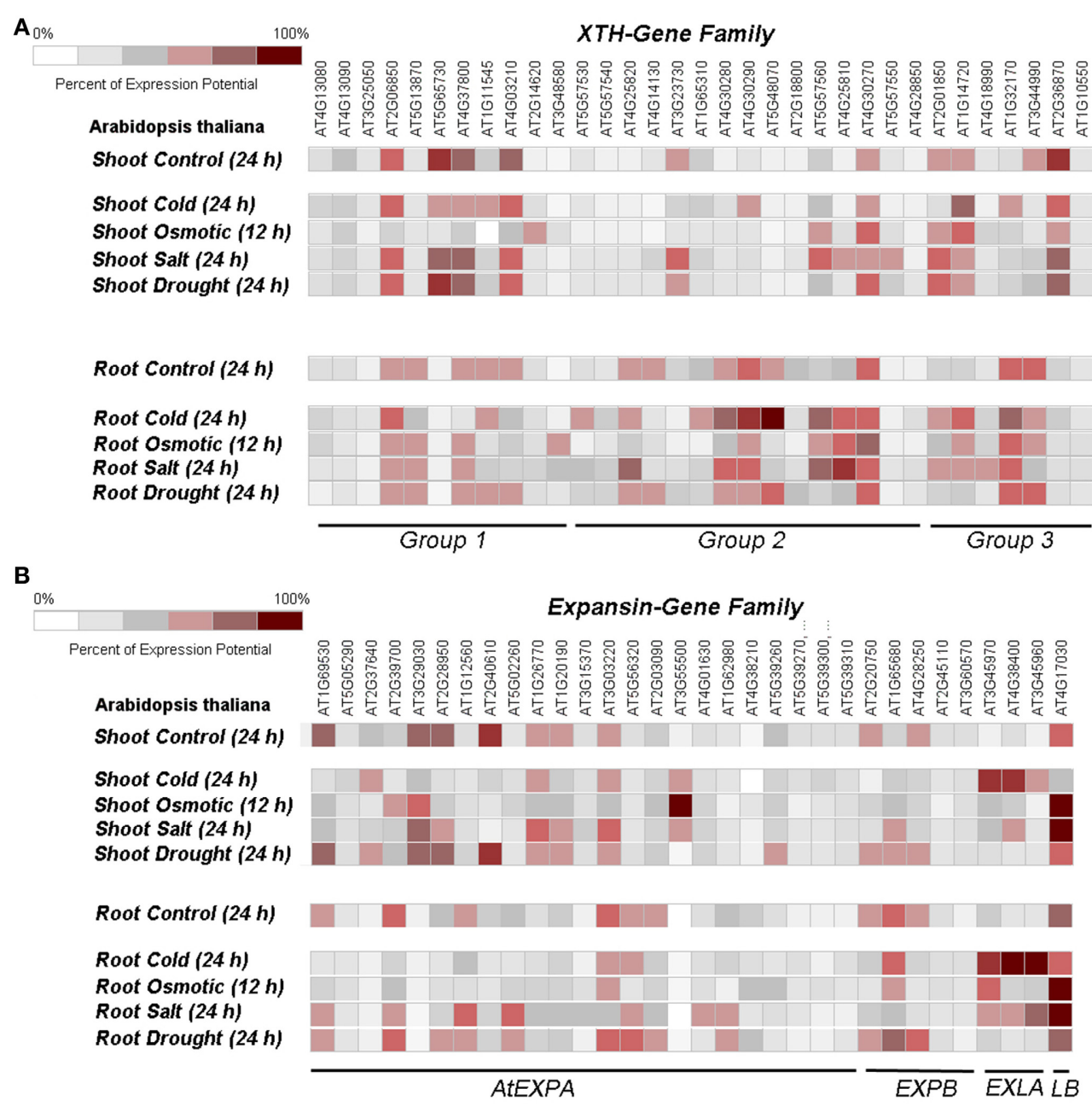

FIGURE 1 | Heat map of expansin and XTH gene expression under abiotic stress for (A) XTH gene family and (B) expansin gene family. The XTH gene family is classified according to Rose et al. (2002), the expansins are classified according to Lee et al.
(2001). Most but not all members are present on the Affimetrix ATH1 chip. The microarrays from the Atgenexpress dataset were used and visualized using the GENEVESTIGATOR software Kilian et al. (2007). 
cell walls. One revised model comes to the conclusion that only a minor portion of the xyloglucan, which is not accessible to $\mathrm{XTH}$ enzymes, is involved in cellulose interaction. Using a creep cell wall extension assay Park and Cosgrove (2012) showed that significant creep was only observed with glucanases which also cleave cellulose beside xyloglucan, suggesting that the tight connection must be modified for extension of the wall. This model however does not exclude the possibility that xyloglucan, which is at a given time point accessible for XTH, later becomes part of the inaccessible xyloglucan involved in the strong network with cellulose.

\section{EXPANSINS}

Expansin genes are also often transcriptionally upregulated by abiotic stress conditions. Motivated by such findings Han et al. (2012) overexpressed a wheat $\beta$-expansin (TaEXPB23) in tobacco. Roots of overexpressor lines developed far better under high salt conditions than wild type tobacco seedlings. It was suggested that seedlings with increased expansin expression have a higher water retention ability, though the possible mechanism as well as the potential change in the cell walls remain unclear. The overexpression of expansin A4 from rose in Arabidopsis leads to higher germination rates under salt stress, longer roots and an increase of lateral roots (Lu et al., 2013). Furthermore, the overexpressing lines are more drought tolerant and recover after the stress, whereas all wild type plants died (Dai et al., 2012). The gene was originally identified by the strong induction in rose petals undergoing dehydration. Knockout of the Arabidopsis expansin like gene AtEXLA2 leads to plants with longer roots than the wild type under normal growth conditions but renders the roots to be more sensitive to salt stress (Abuqamar et al., 2013). This is in line with previous studies which suggest the necessity of a balanced expansin activity for normal cell growth and wall remodeling.

Rice plants stop to elongate the internodial sections under drought stress leading to stunted plants. To unravel the process Todaka et al. (2012) searched for drought regulated genes and identified the transcription factor OsPIL1 as a key regulator in this process. The gene for OsPIL1 is down-regulated under drought. They identified a number of target genes, including several expansin genes. Using a OsEXPA4A::GUS reporter gene construct they demonstrated a strong directly OsPill-dependent induction of OsEXP4A by coexpression of the transcription factor in a rice protoplast system. Ectopic expression of OsPIL1 leads to rice plants with long internodes, whereas repression of the gene results in very short plants suggesting that the coordinated expression of expanins among other genes is mainly responsible for internodial cell length and thus for plant height.

In plants both, expansins and XTH, are present as a larger gene family with 35 members (Lee et al., 2001) for expansins and 33 members for XTH (Rose et al., 2002). Figure 1 shows the relative expression rate of the whole gene family in control shoots and roots as well as under different abiotic stress conditions. Note that not all members are represented on the ATH1-microarray chip. Only the dataset from Atgenexpress was used (Kilian et al., 2007). The heat map shows that only a few members of each gene family respond to each stress factor and it also points to different responses in shoots and roots.
Growth of plant organs under stress is apparently a conflict between stiffening of cell walls by cross-linking and loosening them by ROS, expansins and XTH. A possible simplified model for growth under abiotic stress is presented in Figure 2. The frequently observed growth arrest under abiotic stress may be caused by cross-linking of glycoproteins and phenolics esterified with hemicellulose polymers. This process requires ROS, the activity of peroxidases and substrates for the enzyme in balanced quantities. The cross-linking results in a dense network possibly preventing the undisturbed access of expansins and XTH to the xyloglucan substrate (Figure 2B). If ROS production continues and all cross-linkable substrates are used up by previous peroxidase activity, elevated ROS-levels may cause radical mediated cleavage of polymer chains (Figure 2C). This allows growth again as the $\mathrm{OH}^{\circ}$-radical mediated cell wall loosening process is functionally equivalent to growth in unstressed plants, in which enzymes like expansins and XTH are responsible for cell wall loosening.

\section{CHANGES IN CELL WALL COMPOSITION CAUSED BY ABIOTIC STRESS}

The pectins are often modified in plants exposed to drought stress. Leucci et al. (2008) compared the cell wall of two wheat cultivars differing in their tolerance toward drought stress under stress conditions. The major finding was the increase in side chains of the pectic polymers rhamnogalacturonan I and II (RGI and RGII), possibly because the pectins form hydrated gels which limit the damage to cells (Leucci et al., 2008). Furthermore, the biosynthesis of pectic polymers under drought stress was less affected in the tolerant cultivar (Piro et al., 2003). A similar study with wheat seedlings comparing a drought sensitive with a tolerant line also showed more pectins in the tolerant cultivar, especially in young seedlings (Konno et al., 2008). A comparison of the cell wall composition of root tips from two soybean cultivars showed far higher levels of pectins in the salt tolerant cultivar than in the sensitive line, suggesting that the higher pectin content is beneficial for root growth under salt stress conditions (An et al., 2014). Older plant material from two wheat cultivars with different salt tolerance was compared by Uddin et al. (2013). Unesterified uronic acids increased upon salt stress in both cultivars. However, the increase in uronic acids in the salt tolerant cultivar was slower and stopped at a lower level compared to the sensitive line. The method did not allow discriminating between galacturonic acid from pectins and glucuronic acid from the arabinoxylans. Thus, the exact change in the cell wall remains to be determined.

Rakszegi et al. (2014) compared the cell wall in three wheat cultivars, all tolerant to heat and drought, though at a different level. The major finding was the increase in the dietary fiber arabinoxylan in all cultivars under both stress conditions.

Frost tolerance of different Miscanthus genotypes is associated with compositional changes in the cell wall. The amount of mixed-linked glycans strongly increases in all cultivars after cold acclimatization. The sum of galacturonic and glucuronic acid however increases in frost sensitive lines but decreases in the tolerant one. All lines respond with a dramatic increase of cinnamyl alcohol dehydrogenase after cold acclimatization suggesting that 


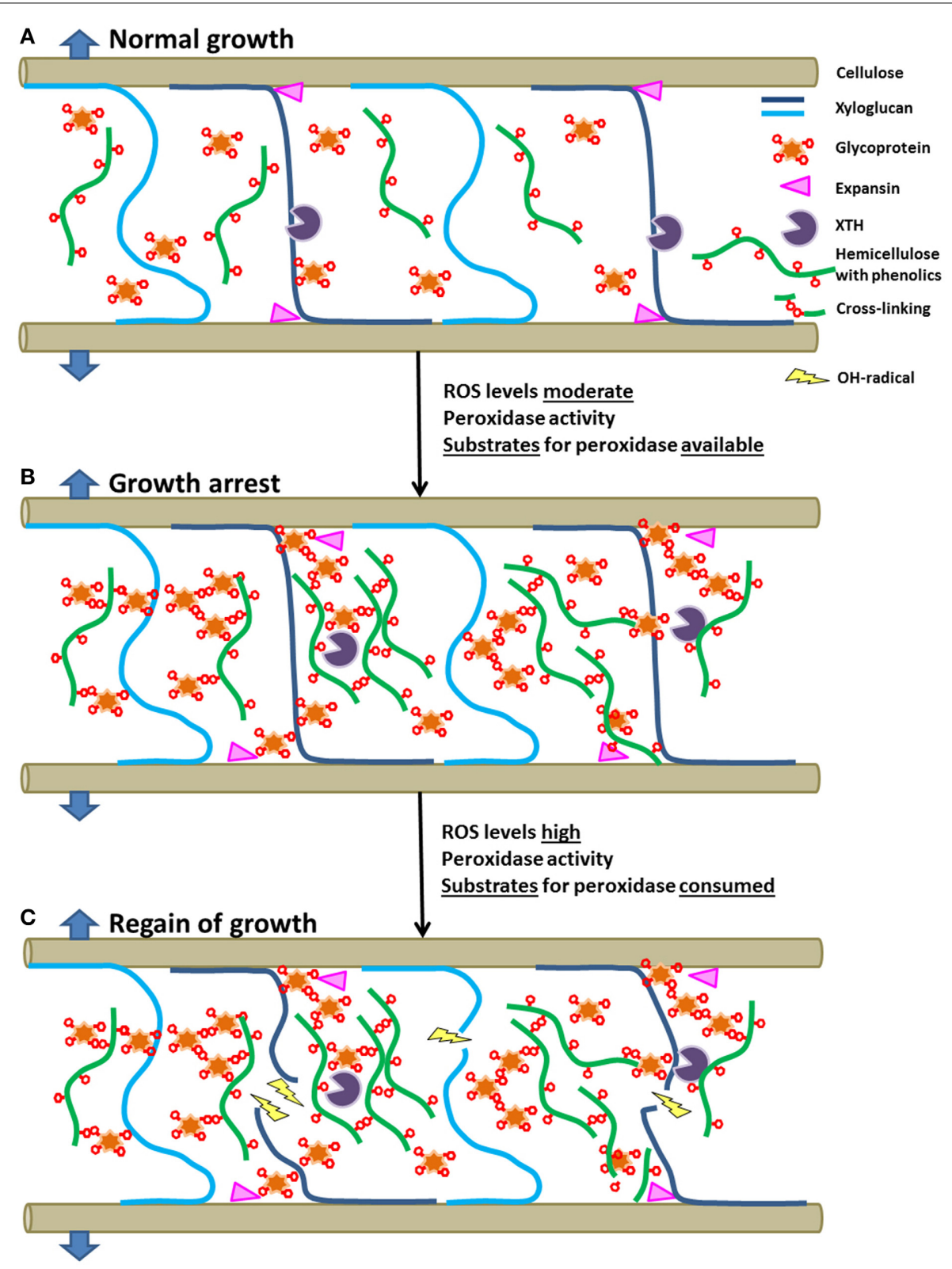

FIGURE 2 | Model of growth of cell walls in unstressed conditions (A), plants under abiotic stress showing growth arrest (B), and tolerant plants overcoming the growth arrest by using ROS-mediated cleavage of cell wall polymers (C) (see text for details).

enhanced lignification is associated with cold temperature treatment (Domon et al., 2013). The changes in lignin content and composition caused by various stress factors was recently reviewed (Magalhaes Silva Moura et al., 2010).

\section{ARE RESURRECTION PLANTS A MODEL FOR CELL WALL ADAPTION UNDER LIMITED WATER AVAILABILITY?}

Resurrection plants survive dehydration of their vegetative tissues to air dry state for extended periods and recover full metabolic competence upon rehydration (Rascio and La Rocca, 2005; Moore et al., 2009; Farrant and Moore, 2011; Gechev et al., 2012; Dinakar and Bartels, 2013). The water loss may be higher than $90 \%$ and is associated with a drastic shrinkage of cell volume. The physiological changes have been studied intensively in some model resurrection plants like Craterostigma plantagineum or Xerophyta viscosa. Analysis of cell walls from resurrection plants either in the hydrated or the desiccated stage revealed species specific differences (Moore et al., 2013). Upon desiccation several species have increased levels of arabinose, which are found in fractions associated with pectins and arabino-galactan-proteins. High arabinan levels are also present in the cell wall of guard cells from Commelina communis (Jones et al., 2003), where they are believed to be responsible for the maintenance of fluidity within the pectin network of the cell wall. A study with intact RG-I from potato 
clearly showed by NMR techniques, that arabinan side chains are hydrated faster than galactan side chains (Larsen et al., 2011). Therefore, a high arabinan amount will readily rehydrate cell walls after drought.

Cell walls of seeds dry out during maturation and a number of seed cell walls also contain higher arabinan levels than the vegetative tissue (Mosele et al., 2011; Gribaa et al., 2013). During germination the arabinan is largely metabolized and serves as a precursor for the synthesis of new wall polymers or arabinogalactan proteins upon activation to UDP-arabinose (Gomez et al., 2009). The high arabinan levels in seed cell walls as well as in desiccated resurrection plants has led to two conclusions. First of all, the arabinans likely fulfill a function as pectic plasticizers to keep the cell wall flexible under abiotic stress (Moore et al., 2013). Second, the mechanism of high arabinan in cell walls from drying tissue is an invention of seeds which was later adopted by resurrection plants. Whether the plasticizer hypothesis fits for a broad variety of plants needs to be addressed in future. An increase in arabinose for instance was not found in the resurrections plants Xerophyta viscosa or X. humilis (Moore et al., 2013). Arabidopsis mur-4 mutants in the enzyme UDP-xylose epimerase, which provides UDP-arabinose as a precursor for polymer synthesis, have extremely low levels of arabinose in their cell walls. The reduction was investigated in different tissues showing a 50-75\% decrease in arabinose (Burget and Reiter, 1999). However, mur-4 mutants show no visible changes in the phenotype, have viable seeds and a normal seed set (Burget et al., 2003), which is not expected if the arabinan plasticizer role is critical for desiccating cell walls during seed maturation.

\section{CELL WALL INTEGRITY CONTROL}

The perception of abiotic stress in the cell wall likely involves members of different receptor-like kinases, comprising a very large family of integral plasma membrane proteins. These receptor-like kinases are believed to perceive changes of the environment in the extracellular space and transmit their signal into the cell, using either second messengers, reactive oxygen species, interfering with abscisic acid signaling or by phosphorylating transcription factors or other unidentified signaling proteins (Lindner et al., 2012; Wolf et al., 2012; Osakabe et al., 2013; Doblin et al., 2014). Many of the genes for receptor-like kinases are induced by abiotic stress itself, thereby amplifying the signal for the necessary stress adaption response (Lindner et al., 2012). A long known example for this is RPK1 from Arabidopsis. Constitutive expression of RPK1 causes an upregulation of a number of stress induced genes and results in an enhanced abiotic stress tolerance (Osakabe et al., 2010). Furthermore, target genes of RPK1 are upregulated in a similar fashion by overexpression of RPK1 as observed by applying stress factors like drought, salt, cold, or heat. The same RPK1 was recently identified as a major determinant for the regeneration frequency of shoots from Arabidopsis calli, a process that is unrelated to abiotic stress but may be linked to abscisic acid signaling (Motte et al., 2014). This raises the question whether RPK1 is a primary receptor for abiotic stress or whether it is involved in transducing the stress signal. Unfortunately, the mechanism by which receptor-like kinases perceive the environmental stress remains to be elucidated. A second group of cell wall integrity receptors is the CrRLK1 family originally identified in Catharanthus roseus. The well-studied members of this group in Arabidopsis include FERONIA (FER) (Huck et al., 2003), THESEUS (THE1) (Hematy et al., 2007) and HERKULES (HERK1, HERK2) (Guo et al., 2009). FER is involved in controlling pollen tube growth and finally rupture during fertilization, a process requiring ROS in particular $\mathrm{OH}^{\circ}$ radicals (Duan et al., 2014). fer-mutants show a reduced cell length in hypocotyls (Deslauriers and Larsen, 2010). Reduced cell elongation phenotypes were also found for mutants in the1 and herk1 when both mutants were combined. Though CrRLK are primarily involved in controlling cell wall integrity under normal physiological conditions, they might provide a framework for the control of cell walls under abiotic stress. Common is the biochemical activation of NADPH-oxidases of the $\mathrm{RBOH}$-family as well as the induction of peroxidase genes. For the formation of localized lignin deposition in the Casparian stripe an interaction of peroxidases and superoxide producing NADPH-oxidases was shown recently (Lee et al., 2013).

\section{BORON STRESS OF PLANTS}

Boron is an essential plant micronutrient required for crosslinking side chains of pectin RGII. It forms diesters between apiose residues (Ishii et al., 1999), the first sugar of some RGII side chains and thereby stabilizes the pectic network and the cell wall itself. Boron deficiency in crop plants is associated with an increase in thickness of the cell wall often referred to as the swollen cell wall phenotype. Thus, the increase in thickness is not caused by deposition of more carbohydrate polymers but by an increase of the pore size of the cell wall (Fleischer et al., 1999). A similar phenotype is observed in plants which have a reduced availability of UDP-apiose and thus less side chains in RGII, though the boron availability is normal (Ahn et al., 2006; Reboul et al., 2011).

Plants grown under limiting boron concentrations are frequently observed on soils with high rain falls, which leach out the boric acid released from rocks. They exhibit pleiotropic phenotypes like inhibition of growth, damage in xylem vessels, and disturbance of plasma membrane transport processes covered by recent reviews (Camacho-Cristobal et al., 2008; Wimmer and Eichert, 2013). In an attempt to dissect the response Koshiba et al. (2009) mimicked boron deprivation in fast growing tobacco BY2 cell cultures by changing the culture medium. Within $12 \mathrm{~h}$ of boron deficiency the first cells undergo programmed cell death accompanied by the production of ROS and lipid break down products (Koshiba et al., 2009). This suggests that the drastic change in cell wall architecture activates the cell wall quality control system to a level which promotes programmed cell death as a response. Similarly, virus mediated silencing of UDPapiose/UDP-xylose synthases in tobacco cause a strong increase in ROS and cell death in tobacco leaves (Ahn et al., 2006). Boron needs to be present in an optimal concentration because too high levels of boron are phytotoxic. This observation was recently addressed by the finding that normal boron levels also cross-link glycosylinositol phosphorylceramides of the plasma membrane with arabinogalactan proteins of the cell wall, thereby attaching the membrane to the cell wall (Voxeur and Fry, 2014). 
High concentrations of boron disrupt this interaction which may explain the phytotoxicity of high levels of boron. The many phenotypes observed with either too low or too high concentrations of boron have stimulated a discussion that proposes a signaling function for boron (Goldbach and Wimmer, 2007; GonzalezFontes et al., 2008, 2014). Plants grown under boron deficiency will likely activate a part of the cell wall integrity control system, which might then activate signaling pathways indirectly observed as boron mediated signaling.

\section{CONCLUSIONS}

The cell wall is clearly affected by many abiotic stress conditions. A common plant response is the production of ROS and an increase in the activity of peroxidases, XTH and expansins. Most data come from transcriptome analysis rather than biochemical experiments. The balance between the formation of ROS and the transcriptional changes for cell wall remodeling enzymes seems to be important for the outcome, either growth arrest in salt and drought sensitive cultivars or a continuation of (preferentially root) growth, though with a reduced rate. Surprisingly little is known about changes in the cell wall itself, a challenge for a better understanding of abiotic stress tolerance.

\section{ACKNOWLEDGMENTS}

The funding of the publication cost for this article by the open access fond of Salzburg University is gratefully acknowledged.

\section{REFERENCES}

Abuqamar, S., Ajeb, S., Sham, A., Enan, M. R., and Iratni, R. (2013). A mutation in the expansin-like A2 gene enhances resistance to necrotrophic fungi and hypersensitivity to abiotic stress in Arabidopsis thaliana. Mol. Plant Pathol. 14, 813-827. doi: 10.1111/mpp.12049

Ahn, J. W., Verma, R., Kim, M., Lee, J. Y., Kim, Y. K., Bang, J. W., et al. (2006). Depletion of UDP-D-apiose/UDP-D-xylose synthases results in rhamnogalacturonan-II deficiency, cell wall thickening, and cell death in higher plants. J. Biol. Chem. 281, 13708-13716. doi: 10.1074/jbc.M512403200

An, P., Li, X., Zheng, Y., Matsuura, A., Abe, J., Eneji, A. E., et al. (2014). Effects of $\mathrm{NaCl}$ on root growth and cell wall composition of two soya bean cultivars with contrasting salt tolerance. J. Agr. Crop Sci. 200, 212-218. doi: 10.1111/jac.12060

Atkinson, N. J., and Urwin, P. E. (2012). The interaction of plant biotic and abiotic stresses: from genes to the field. J. Exp. Bot. 63, 3523-3543. doi: 10.1093/jxb/ers100

Braidwood, L., Breuer, C., and Sugimoto, K. (2014). Mybody is a cage: mechanisms and modulation of plant cell growth. New Phytol. 201, 388-402. doi: 10.1111/nph.12473

Burget, E. G., and Reiter, W. D. (1999). The mur4 mutant of arabidopsis is partially defective in the de novo synthesis of uridine diphospho L-arabinose. Plant Physiol. 121, 383-389. doi: 10.1104/pp.121.2.383

Burget, E. G., Verma, R., Molhoj, M., and Reiter, W. D. (2003). The biosynthesis of L-arabinose in plants: molecular cloning and characterization of a Golgi-localized UDP-D-xylose 4-epimerase encoded by the MUR4 gene of Arabidopsis. Plant Cell 15, 523-531. doi: 10.1105/tpc.008425

Burr, S. J., and Fry, S. C. (2009). Feruloylated arabinoxylans are oxidatively crosslinked by extracellular maize peroxidase but not by horseradish peroxidase. $\mathrm{Mol}$. Plant 2, 883-892. doi: 10.1093/mp/ssp044

Camacho-Cristobal, J. J., Rexach, J., and Gonzalez-Fontes, A. (2008). Boron in plants: deficiency and toxicity. J. Integr. Plant Biol. 50, 1247-1255. doi: 10.1111/j.1744-7909.2008.00742.x

Carpita, N. C., and Gibeaut, D. M. (1993). Structural models of primary-cell walls in flowering plants-consistency of molecular-structure with the physicalproperties of the walls during growth. Plant J. 3, 1-30. doi: 10.1111/j.1365313X.1993.tb00007.x

Cavalier, D. M., Lerouxel, O., Neumetzler, L., Yamauchi, K., Reinecke, A., Freshour, G., et al. (2008). Disrupting two Arabidopsis thaliana xylosyltransferase genes results in plants deficient in xyloglucan, a major primary cell wall component. Plant Cell 20, 1519-1537. doi: 10.1105/tpc.108.059873

Chan, Z., Grumet, R., and Loescher, W. (2011). Global gene expression analysis of transgenic, mannitol-producing, and salt-tolerant Arabidopsis thaliana indicates widespread changes in abiotic and biotic stress-related genes. J. Exp. Bot. 62, 4787-4803. doi: 10.1093/jxb/err130

Cho, S. K., Kim, J. E., Park, J. A., Eom, T. J., and Kim, W. T. (2006). Constitutive expression of abiotic stress-inducible hot pepper $\mathrm{CaXTH} 3$, which encodes a xyloglucan endotransglucosylase/hydrolase homolog, improves drought and salt tolerance in transgenic Arabidopsis plants. FEBS Lett. 580, 3136-3144. doi: 10.1016/j.febslet.2006.04.062

Choi, J. Y., Seo, Y. S., Kim, S. J., Kim, W. T., and Shin, J. S. (2011). Constitutive expression of CaXTH3, a hot pepper xyloglucan endotransglucosylase/hydrolase, enhanced tolerance to salt and drought stresses without phenotypic defects in tomato plants (Solanum lycopersicum cv. Dotaerang). Plant Cell Rep. 30, 867-877. doi: 10.1007/s00299-010-0989-3

Cosgrove, D. J. (1997). Assembly and enlargement of the primary cell wall in plants. Ann. Rev. Cell Dev. Biol. 13, 171-201. doi: 10.1146/annurev.cellbio.13.1.171

Cosgrove, D. J., and Jarvis, M. C. (2012). Comparative structure and biomechanics of plant primary and secondary cell walls. Front. Plant Sci. 3:204. doi: 10.3389/fpls.2012.00204

Csiszar, J., Galle, A., Horvath, E., Dancso, P., Gombos, M., Vary, Z., et al. (2012). Different peroxidase activities and expression of abiotic stress-related peroxidases in apical root segments of wheat genotypes with different drought stress tolerance under osmotic stress. Plant Physiol. Biochem. 52, 119-129. doi: 10.1016/j.plaphy.2011.12.006

Csiszar, J., Pinter, B., Kolbert, Z., Erdei, L., and Tari, I. (2008). Peroxidase activities in root segments of wheat genotypes under osmotic stress. Acta Biol. Szeged. 52, $155-156$.

Dai, F., Zhang, C., Jiang, X., Kang, M., Yin, X., Lu, P., et al. (2012). RhNAC2 and RhEXPA4 are involved in the regulation of dehydration tolerance during the expansion of rose petals. Plant Physiol. 160, 2064-2082. doi: 10.1104/pp.112.207720

Dani, V., Simon, W. J., Duranti, M., and Croy, R. R. D. (2005). Changes in the tobacco leaf apoplast proteome in response to salt stress. Proteomics 5, 737-745. doi: 10.1002/pmic.200401119

Deslauriers, S. D., and Larsen, P. B. (2010). FERONIA Is a key modulator of brassinosteroid and ethylene responsiveness in Arabidopsis hypocotyls. Mol. Plant 3, 626-640. doi: 10.1093/mp/ssq015

Dinakar, C., and Bartels, D. (2013). Desiccation tolerance in resurrection plants: new insights from transcriptome, proteome, and metabolome analysis. Front. Plant Sci. 4:482. doi: 10.3389/fpls.2013.00482

Doblin, M. S., Johnson, K. L., Humphries, J., Newbigin, E. J., and Bacic, A. (2014). Are designer plant cell walls a realistic aspiration or will the plasticity of the plant's metabolism win out? Curr. Opin. Biotechnol. 26, 108-114. doi: 10.1016/j.copbio.2013.11.012

Domon, J.-M., Baldwin, L., Acket, S., Caudeville, E., Arnoult, S., Zub, H., et al. (2013). Cell wall compositional modifications of Miscanthus ecotypes in response to cold acclimation. Phytochemistry 85, 51-61. doi: 10.1016/j.phytochem.2012.09.001

Dong, J., Jiang, Y., Chen, R., Xu, Z., and Gao, X. (2011). Isolation of a novel xyloglucan endotransglucosylase (OsXET9) gene from rice and analysis of the response of this gene to abiotic stresses. Afr. J. Biotechnol. 10, 17424-17434. doi: $10.5897 /$ ajb11.1242

Duan, Q., Kita, D., Johnson, E. A., Aggarwal, M., Gates, L., Wu, H.-M., et al. (2014). Reactive oxygen species mediate pollen tube rupture to release sperm for fertilization in Arabidopsis. Nat. Commun. 5:3129. doi: 10.1038/ ncomms 4129

Farrant, J. M., and Moore, J. P. (2011). Programming desiccation-tolerance: from plants to seeds to resurrection plants. Curr. Opin. Plant Biol. 14, 340-345. doi 10.1016/j.pbi.2011.03.018

Fleischer, A., O’Neill, M. A., and Ehwald, R. (1999). The pore size of nongraminaceous plant cell walls is rapidly decreased by borate ester cross-linking of the pectic polysaccharide rhamnogalacturonan I. Plant Physiol. 121, 829-838.

Fry, S. C. (1998). Oxidative scission of plant cell wall polysaccharides by ascorbateinduced hydroxyl radicals. Biochem. J. 332, 507-515.

Gechev, T. S., Dinakar, C., Benina, M., Toneva, V., and Bartels, D. (2012). Molecular mechanisms of desiccation tolerance in resurrection plants. Cell. Mol. Life Sci. 69, 3175-3186. doi: 10.1007/s00018-012-1088-0 
Goldbach, H. E., and Wimmer, M. A. (2007). Boron in plants and animals: is there a role beyond cell-wall structure? J. Plant Nutr. Soil Sci. 170, 39-48. doi: 10.1002/jpln.200625161

Gomez, L. D., Steele-King, C. G., Jones, L., Foster, J. M., Vuttipongchaikij, S., and McQueen-Mason, S. J. (2009). Arabinan metabolism during seed development and germination in Arabidopsis. Mol. Plant 2, 966-976. doi: 10.1093/mp/ssp050

Gonzalez-Fontes, A., Navarro-Gochicoa, M. T., Camacho-Cristobal, J. J., HerreraRodriguez, M. B., Quiles-Pando, C., and Rexach, J. (2014). Is $\mathrm{Ca}^{2+}$ involved in the signal transduction pathway of boron deficiency? New hypotheses for sensing boron deprivation. Plant Sci. 217, 135-139. doi: 10.1016/j.plantsci.2013.12.011

Gonzalez-Fontes, A., Rexach, J., Navarro-Gochicoa, M. T., Herrera-Rodriguez, M. B., Beato, V. M., Camacho-Cristobal, J. J., et al. (2008). Is boron involved solely in structural roles in vascular plants? Plant Signal. Behav. 3, 24-26. doi: $10.4161 /$ psb.3.1.4812

Gribaa, A., Dardelle, F., Lehner, A., Rihouey, C., Burel, C., Ferchichi, A., et al. (2013). Effect of water deficit on the cell wall of the date palm (Phoenix dactylifera 'Deglet nour', Arecales) fruit during development. Plant Cell Environ. 36, 1056-1070. doi: 10.1111/pce.12042

Guo, H., Li, L., Ye, H., Yu, X., Algreen, A., and Yin, Y. (2009). Three related receptor-like kinases are required for optimal cell elongation in Arabidopsis thaliana. Proc. Natl. Acad. Sci. U.S.A. 106, 7648-7653. doi: 10.1073/pnas.0812 346106

Han, Y. Y., Li, A. X., Li, F., Zhao, M. R., and Wang, W. (2012). Characterization of a wheat (Triticum aestivum L.) expansin gene, TaEXPB23, involved in the abiotic stress response and phytohormone regulation. Plant Physiol. Biochem. 54, 49-58. doi: 10.1016/j.plaphy.2012.02.007

Hayashi, T. (1989). Xyloglucans in the primary-cell wall. Annu. Rev. Plant Physiol. Plant Mol. Biol. 40, 139-168. doi: 10.1146/annurev.pp.40.060189.001035

Hematy, K., Sado, P.-E., Van Tuinen, A., Rochange, S., Desnos, T., Balzergue, S., et al. (2007). A receptor-like kinase mediates the response of Arabidopsis cells to the inhibition of cellulose synthesis. Curr. Biol. 17, 922-931. doi: 10.1016/j.cub.2007.05.018

Huck, N., Moore, J. M., Federer, M., and Grossniklaus, U. (2003). The Arabidopsis mutant feronia disrupts the female gametophytic control of pollen tube reception. Development 130, 2149-2159. doi: 10.1242/dev.00458

Ishii, T., Matsunaga, T., Pellerin, P., O’Neill, M. A., Darvill, A., and Albersheim, P. (1999). The plant cell wall polysaccharide rhamnogalacturonan II selfassembles into a covalently cross-linked dimer. J. Biol. Chem. 274, 13098-13104. doi: 10.1074/jbc.274.19.13098

Jones, L., Milne, J. L., Ashford, D., and McQueen-Mason, S. J. (2003). Cell wall arabinan is essential for guard cell function. Proc. Natl. Acad. Sci. U.S.A. 100, 11783-11788. doi: 10.1073/pnas. 1832434100

Kieffer, F., Lherminier, J., Simon-Plas, F., Nicole, M., Paynot, M., Elmayan, T., et al. (2000). The fungal elicitor cryptogein induces cell wall modifications on tobacco cell suspension. J. Exp. Bot. 51, 1799-1811. doi: 10.1093/jexbot/51.352.1799

Kilian, J., Whitehead, D., Horak, J., Wanke, D., Weinl, S., Batistic, O., et al. (2007). The AtGenExpress global stress expression data set: protocols, evaluation and model data analysis of UV-B light, drought and cold stress responses. Plant J. 50, 347-363. doi: 10.1111/j.1365-313X.2007.03052.x

Kim, Y.-H., Kim, C. Y., Song, W.-K., Park, D.-S., Kwon, S.-Y., Lee, H.-S., et al. (2008). Overexpression of sweetpotato swpa4 peroxidase results in increased hydrogen peroxide production and enhances stress tolerance in tobacco. Planta 227, 867-881. doi: 10.1007/s00425-007-0663-3

Komatsu, S., and Yanagawa, Y. (2013). Cell wall proteomics of crops. Front. Plant Sci. 4:17. doi: 10.3389/fpls.2013.00017

Kong, F.-J., Oyanagi, A., and Komatsu, S. (2010). Cell wall proteome of wheat roots under flooding stress using gel-based and LC MS/MS-based proteomics approaches. Biochim. Et Biophys. Acta Proteins Proteomics 1804, 124-136. doi: 10.1016/j.bbapap.2009.09.023

Konno, H., Yamasaki, Y., Sugimoto, M., and Takeda, K. (2008). Differential changes in cell wall matrix polysaccharides and glycoside-hydrolyzing enzymes in developing wheat seedlings differing in drought tolerance. J. Plant Physiol. 165, 745-754. doi: 10.1016/j.jplph.2007.07.007

Koshiba, T., Kobayashi, M., and Matoh, T. (2009). Boron Nutrition of Tobacco BY-2 Cells. V. Oxidative damage is the major cause of cell death induced by boron deprivation. Plant Cell Physiol. 50, 26-36. doi: 10.1093/pcp/ pcn 184
Larsen, F. H., Byg, I., Damager, I., Diaz, J., Engelsen, S. B., and Ulvskov, P. (2011). Residue Specific hydration of primary cell wall potato pectin identified by solid-state C-13 single-pulse MAS and CP/MAS NMR spectroscopy. Biomacromolecules 12, 1844-1850. doi: 10.1021/bm2001928

Lee, S. G., and Aronoff, S. (1966). Investigations on role of boron in plants.3. Anatomical observation. Plant Physiol. 41:1570. doi: 10.1104/pp.41.10.1570

Lee, Y., Choi, D., and Kende, H. (2001). Expansins: ever-expanding numbers and functions. Curr. Opin. Plant Biol. 4, 527-532. doi: 10.1016/S13695266(00)00211-9

Lee, Y., Rubio, M. C., Alassimone, J., and Geldner, N. (2013). A mechanism for localized lignin deposition in the endodermis. Cell 153, 402-412. doi: 10.1016/j.cell.2013.02.045

Leucci, M. R., Lenucci, M. S., Piro, G., and Dalessandro, G. (2008). Water stress and cell wall polysaccharides in the apical root zone of wheat cultivars varying in drought tolerance. J. Plant Physiol. 165, 1168-1180. doi: 10.1016/j.jplph.2007.09.006

Lindner, H., Mueller, L. M., Boisson-Dernier, A., and Grossniklaus, U. (2012). CrRLK1L receptor-like kinases: not just another brick in the wall. Curr. Opin. Plant Biol. 15, 659-669. doi: 10.1016/j.pbi.2012.07.003

Lindsay, S. E., and Fry, S. C. (2008). Control of diferulate formation in dicotyledonous and gramineous cell-suspension cultures. Planta 227, 439-452. doi: 10.1007/s00425-007-0630-Z

Lu, P. T., Kang, M., Jiang, X. Q., Dai, F. W., Gao, J. P., and Zhang, C. Q. (2013). RhEXPA4, a rose expansin gene, modulates leaf growth and confers drought and salt tolerance to Arabidopsis. Planta 237, 1547-1559. doi: 10.1007/s00425013-1867-3

MacAdam, J. W., and Grabber, J. H. (2002). Relationship of growth cessation with the formation of diferulate cross-links and p-coumaroylated lignins in tall fescue leaf blades. Planta 215, 785-793. doi: 10.1007/s00425-0020812-7

Magalhaes Silva Moura, J. C., Valencise Bonine, C. A., Fernandes Viana, J. d. O., Dornelas, M. C., and Mazzafera, P. (2010). Abiotic and biotic stresses and changes in the lignin content and composition in plants. J. Integr. Plant Biol. 52, 360-376. doi: 10.1111/j.1744-7909.2010.00892.x

Maia, J. M., Voigt, E. L., Ferreira-Silva, S. L. A. d. Fontenele, V., Macedo, C. E. C., and Silveira, J. A. G. (2013). Differences in cowpea root growth triggered by salinity and dehydration are associated with oxidative modulation involving types I and III peroxidases and apoplastic ascorbate. J. Plant Growth Regul. 32, 376-387. doi: 10.1007/s00344-012-9308-2

Miller, G., Suzuki, N., Ciftci-Yilmaz, S., and Mittler, R. (2010). Reactive oxygen species homeostasis and signalling during drought and salinity stresses. Plant Cell and Environ. 33, 453-467. doi: 10.1111/j.1365-3040.2009.02041.x

Mittler, R., and Blumwald, E. (2010). Genetic engineering for modern agriculture: challenges and perspectives. Ann. Rev. Plant Biol. 61, 443-462. doi: 10.1146/annurev-arplant-042809-112116

Mohnen, D. (2008). Pectin structure and biosynthesis. Curr. Opin. Plant Biol. 11, 266-277. doi: 10.1016/j.pbi.2008.03.006

Moore, J. P., Le, N. T., Brandt, W. F., Driouich, A., and Farrant, J. M. (2009). Towards a systems-based understanding of plant desiccation tolerance. Trends Plant Sci. 14, 110-117. doi: 10.1016/j.tplants.2008.11.007

Moore, J. P., Nguema-Ona, E. E., Vicre-Gibouin, M., Sorensen, I., Willats, W. G. T., Driouich, A., et al. (2013). Arabinose-rich polymers as an evolutionary strategy to plasticize resurrection plant cell walls against desiccation. Planta 237, 739-754. doi: 10.1007/s00425-012-1785-9

Mosele, M. M., Hansen, A. S., Engelsen, S. B., Diaz, J., Sorensen, I., Ulvskov, P., et al. (2011). Characterisation of the arabinose-rich carbohydrate composition of immature and mature marama beans (Tylosema esculentum). Phytochemistry 72, 1466-1472. doi: 10.1016/j.phytochem.2011.03.027

Motte, H., Vercauteren, A., Depuydt, S., Landschoot, S., Geelen, D., Werbrouck, S., et al. (2014). Combining linkage and association mapping identifies RECEPTOR-LIKE PROTEIN KINASE1 as an essential Arabidopsis shoot regeneration gene. Proc. Natl. Acad. Sci. U.S.A. 111, 8305-8310. doi: 10.1073/pnas.1404978111

Nishiyama, R., Le, D. T., Watanabe, Y., Matsui, A., Tanaka, M., Seki, M., et al. (2012). Transcriptome analyses of a salt-tolerant cytokinin-deficient mutant reveal differential regulation of salt stress response by cytokinin deficiency. PLoS ONE 7:32124. doi: 10.1371/journal.pone.0032124

Osakabe, Y., Mizuno, S., Tanaka, H., Maruyama, K., Osakabe, K., Todaka, D., et al. (2010). Overproduction of the membrane-bound receptor-like protein kinase 
1, RPK1, enhances abiotic stress tolerance in Arabidopsis. J. Biol. Chem. 285, 9190-9201. doi: 10.1074/jbc.M109.051938

Osakabe, Y., Yamaguchi-Shinozaki, K., Shinozaki, K., and Lam-Son Phan, T. (2013). Sensing the environment: key roles of membrane-localized kinases in plant perception and response to abiotic stress. J. Exp. Bot. 64, 445-458. doi: 10.1093/jxb/ers354

Park, Y. B., and Cosgrove, D. J. (2012). A revised architecture of primary cell walls based on biomechanical changes induced by substrate-specific endoglucanases. Plant Physiol. 158, 1933-1943. doi: 10.1104/pp.111.192880

Passardi, F., Cosio, C., Penel, C., and Dunand, C. (2005). Peroxidases have more functions than a Swiss army knife. Plant Cell Rep. 24, 255-265. doi: 10.1007/s00299-005-0972-6

Peaucelle, A., Braybrook, S., and Hoefte, H. (2012). Cell wall mechanics and growth control in plants: the role of pectins revisited. Front. Plant Sci. 3:121. doi: 10.3389/fpls.2012.00121

Pechanova, O., Hsu, C.-Y., Adams, J. P., Pechan, T., Vandervelde, L., Drnevich, J., et al. (2010). Apoplast proteome reveals that extracellular matrix contributes to multistress response in poplar. BMC Genomics 11:674. doi: 10.1186/1471-216411-674

Piro, G., Leucci, M. R., Waldron, K., and Dalessandro, G. (2003). Exposure to water stress causes changes in the biosynthesis of cell wall polysaccharides in roots of wheat cultivars varying in drought tolerance. Plant Sci. 165, 559-569. doi: 10.1016/S0168-9452(03)00215-2

Rakszegi, M., Lovegrove, A., Balla, K., Lang, L., Bedo, Z., Veisz, O., et al. (2014). Effect of heat and drought stress on the structure and composition of arabinoxylan and beta-glucan in wheat grain. Carbohydr. Polym. 102, 557-565. doi: 10.1016/j.carbpol.2013.12.005

Ranjan, A., Pandey, N., Lakhwani, D., Dubey, N. K., Pathre, U. V., and Sawant, S. V. (2012). Comparative transcriptomic analysis of roots of contrasting Gossypium herbaceum genotypes revealing adaptation to drought. BMC Genomics 13:680. doi: 10.1186/1471-2164-13-680

Rascio, N., and La Rocca, N. (2005). Resurrection plants: the puzzle of surviving extreme vegetative desiccation. CRC. Crit. Rev. Plant Sci. 24, 209-225. doi: 10.1080/07352680591008583

Reboul, R., Geserick, C., Pabst, M., Frey, B., Wittmann, D., Luetz-Meindl, U., et al. (2011). Down-regulation of UDP-glucuronic acid biosynthesis leads to swollen plant cell walls and severe developmental defects associated with changes in pectic polysaccharides. J. Biol. Chem. 286, 39982-39992. doi: 10.1074/jbc.M111.255695

Reiter, W. D. (2002). Biosynthesis and properties of the plant cell wall. Curr. Opin. Plant Biol. 5, 536-542. doi: 10.1016/S1369-5266(02)00306-0

Renew, S., Heyno, E., Schopfer, P., and Liszkay, A. (2005). Sensitive detection and localization of hydroxyl radical production in cucumber roots and Arabidopsis seedlings by spin trapping electron paramagnetic resonance spectroscopy. Plant J. 44, 342-347. doi: 10.1111/j.1365-313X.2005.02528.x

Rose, J. K., Braam, J., Fry, S. C., and Nishitani, K. (2002). The XTH family of enzymes involved in xyloglucan endotransglucosylation and endohydrolysis: current perspectives and a new unifying nomenclature. Plant Cell Physiol 43, 1421-1435. doi: 10.1093/pcp/pcf171

Rosegrant, M. W., and Cline, S. A. (2003). Global food security: challenges and policies. Science 302, 1917-1919. doi: 10.1126/science.1092958

Schopfer, P. (2001). Hydroxyl radical-induced cell-wall loosening in vitro and in vivo: implications for the control of elongation growth. Plant J. 28, 679-688. doi: 10.1046/j.1365-313x.2001.01187.x

Schopfer, P. (2006). Biomechanics of plant growth. Am. J. Bot. 93, 1415-1425. doi: 10.3732/ajb.93.10.1415

Secenji, M., Lendvai, A., Miskolczi, P., Kocsy, G., Galle, A., Szucs, A., et al. (2010). Differences in root functions during long-term drought adaptation: comparison of active gene sets of two wheat genotypes. Plant Biol. 12, 871-882. doi: 10.1111/j.1438-8677.2009.00295.x
Shinano, T., Komatsu, S., Yoshimura, T., Tokutake, S., Kong, F. J., Watanabe, T., et al. (2011). Proteomic analysis of secreted proteins from aseptically grown rice. Phytochemistry 72, 312-320. doi: 10.1016/j.phytochem.2010. 12.006

Simonovicova, M., Huttova, J., Mistrik, I., Siroka, B., and Tamas, L. (2004) Peroxidase mediated hydrogen peroxide production in barley roots grown under stress conditions. Plant Growth Regul. 44, 267-275. doi: 10.1007/s10725004-4662-0

Skirycz, A., and Inze, D. (2010). More from less: plant growth under limited water. Curr. Opin. Biotechnol. 21, 197-203. doi: 10.1016/j.copbio.2010.03.002

Todaka, D., Nakashima, K., Maruyama, K., Kidokoro, S., Osakabe, Y., Ito, Y., et al. (2012). Rice phytochrome-interacting factor-like protein OsPILl functions as a key regulator of internode elongation and induces a morphological response to drought stress. Proc. Natl. Acad. Sci. U.S.A. 109, 15947-15952. doi: 10.1073/pnas.1207324109

Uddin, M. N., Hanstein, S., Faust, F., Eitenmueller, P. T., Pitann, B., and Schubert, S. (2014). Diferulic acids in the cell wall may contribute to the suppression of shoot growth in the first phase of salt stress in maize. Phytochemistry 102, 126-136. doi: 10.1016/j.phytochem.2014.02.014

Uddin, M. N., Hanstein, S., Leubner, R., and Schubert, S. (2013). Leaf cell-wall components as influenced in the first phase of salt stress in three maize (Zea mays L.) hybrids differing in salt resistance. J. Agr. Crop Sci. 199, 405-415. doi: $10.1111 /$ jac. 12031

Voxeur, A., and Fry, S. C. (2014). Glycosylinositol phosphorylceramides from Rosa cell cultures are boron-bridged in the plasma membrane and form complexes with rhamnogalacturonan I. Plant J. 79, 139-149. doi: 10.1111/tpj.12547

Wakabayashi, K., Soga, K., and Hoson, T. (2012). Phenylalanine ammonia-lyase and cell wall peroxidase are cooperatively involved in the extensive formation of ferulate network in cell walls of developing rice shoots. J. Plant Physiol. 169, 262-267. doi: 10.1016/j.jplph.2011.10.002

Wimmer, M. A., and Eichert, T. (2013). Review: mechanisms for boron deficiencymediated changes in plant water relations. Plant Sci. 203, 25-32. doi: 10.1016/j.plantsci.2012.12.012

Wolf, S., Hematy, K., and Hoefte, H. (2012). Growth control and cell wall signaling in plants. Ann. Rev. Plant Biol. 63, 381-407. doi: 10.1146/annurev-arplant042811-105449

Wu, Y. J., and Cosgrove, D. J. (2000). Adaptation of roots to low water potentials by changes in cell wall extensibility and cell wall proteins. J. Exp. Bot. 51, 1543-1553. doi: 10.1093/jexbot/51.350.1543

Zhu, J., Alvarez, S., Marsh, E. L., LeNoble, M. E., Cho, I.-J., Sivaguru, M., et al. (2007). Cell wall Proteome in the maize primary root elongation zone. II. Region-specific changes in water soluble and lightly ionically bound proteins under water deficit. Plant Physiol. 145, 1533-1548. doi: 10.1104/pp.107.107250

Conflict of Interest Statement: The author declares that the research was conducted in the absence of any commercial or financial relationships that could be construed as a potential conflict of interest.

Received: 08 September 2014; accepted: 14 December 2014; published online: 07 January 2015.

Citation: Tenhaken $R$ (2015) Cell wall remodeling under abiotic stress. Front. Plant Sci. 5:771. doi: 10.3389/fpls.2014.00771

This article was submitted to Plant Physiology, a section of the journal Frontiers in Plant Science.

Copyright (C) 2015 Tenhaken. This is an open-access article distributed under the terms of the Creative Commons Attribution License (CC BY). The use, distribution or reproduction in other forums is permitted, provided the original author(s) or licensor are credited and that the original publication in this journal is cited, in accordance with accepted academic practice. No use, distribution or reproduction is permitted which does not comply with these terms. 